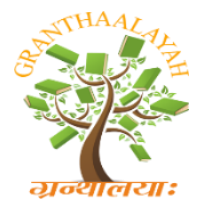

\author{
INTERNATIONAL JOURNAL OF RESEARCH - \\ GRANTHAALAYAH \\ A knowledge Repository
}

Social

\title{
A STUDY ON ATTITUDE TOWARDS LEARNING LANGUAGES AMONG HIGH SCHOOL STUDENTS IN THRISSUR DISTRICT
}

\author{
Praseetha S.V. ${ }^{1}$, Ms. V.A. Malathi ${ }^{1}$ \\ ${ }^{1}$ M.Ed Scholar, RVS College of Education, Sulur, India \\ ${ }^{2} \mathrm{MSc}, \mathrm{M}$ Ed. SET(Edu) RVS College of Education, Sulur, India
}

\begin{abstract}
Attitude is defined as a settled way of thinking or feeling about something. Allport (1954) defines attitude as a "learned disposition to think, feel and behave toward a person (or object) in a particular way." Language is a system of conventional spoken, manual, or written symbols by means of which human beings, as members of a social group and participants in its culture, express themselves. The functions of language include communication, the expression of identity, play imaginative expression and emotional release. This paper is an attempt to identify the attitude towards learning languages among high school students. The investigator adopted the survey method to study the attitude towards learning languages among high school students. The study is based on primary data which was collected from 300 high school students in and around Thrissur district using simple random sampling technique. The findings reveal that there is a difference in the level of attitude towards learning languages among high school students.
\end{abstract}

Keywords: Attitude; Survey Method; Gender; Medium of Instruction; Level of Attitude.

Cite This Article: Praseetha S.V., and Ms. V.A. Malathi. (2019). "A STUDY ON ATTITUDE TOWARDS LEARNING LANGUAGES AMONG HIGH SCHOOL STUDENTS IN THRISSUR DISTRICT." International Journal of Research - Granthaalayah, 7(5), 361-364. https://doi.org/10.29121/granthaalayah.v7.i5.2019.858.

\section{Introduction}

All students are entitled to an education in a positive environment. Anxiety is a normal reaction to certain situations. A small level of anxiety is normal, but severe anxiety can be a serious problem. Academic anxiety can become more detrimental over time. As a student's academic performance suffers, the anxiety level related to certain academic tasks increases (Huberty, 2012). Most teachers will have students with social anxiety and/or academic anxiety. Social anxiety can also affect a student's academic performance. If a student has social anxiety, the student might not be able to complete group tasks or might not feel comfortable asking for help in class. Social anxiety can go 
along with or even lead to academic anxiety. Teaching students self-regulation can reduce anxiety and increase academic performance (Ader \& Erktin, 2010).

\section{Research Design}

The study aimed to identify the attitude towards learning languages among high school students. In the present study survey method was used. The study is based on primary data which is collected from 300 high school students in and around Thrissur district.

\section{Hypothesis: 1}

There will be a difference in the level of attitude towards learning languages among high school students.

Table 4.1: Frequency and percentage difference in the level of attitude towards learning languages among high school students.

\begin{tabular}{|c|c|c|c|c|c|c|c|c|}
\hline \multicolumn{4}{|c|}{ Attitude Towards Learning Languages } \\
\hline \multicolumn{3}{|c|}{ Low } & \multicolumn{3}{c|}{ Moderate } & \multicolumn{3}{|c|}{ High } \\
\hline Q1 & F & \% & Q2 & F & \% & Q3 & F & \% \\
\hline 96 & 79 & $26.33 \%$ & 99 & 137 & $45.66 \%$ & 114 & 84 & $28 \%$ \\
\hline
\end{tabular}

Table :1 exhibits the result of attitude towards learning languages among high school students. According to the table, totally $26.33 \%$ of high school students belong to low level of attitude towards learning languages, $45.66 \%$ of high school students belong to moderate level of attitude towards learning languages and $28 \%$ of high school students belong to high level of attitude towards learning languages. So, the hypothesis 1 is accepted. Thus, it is inferred that there is a difference in the level of attitude towards learning languages among high school students.

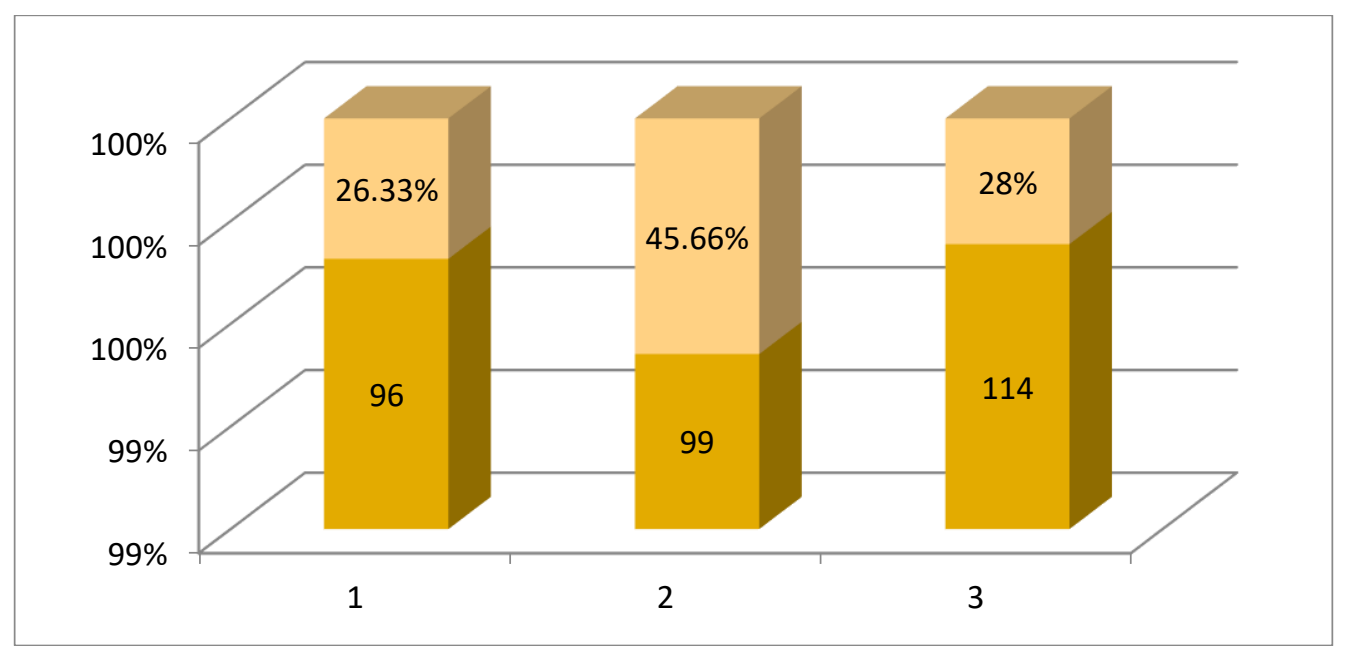

Chart 1: Frequency and Percentage Difference In The Level Of Attitude Towards Learning Languages Among High School Students

1=Low level of attitude towards learning languages-26.33\%

$2=$ Moderate level of attitude towards learning languages $-45.66 \%$

$3=$ High level of attitude towards learning languages $-28 \%$ 


\section{Hypothesis: 2}

There will be a significant mean score difference of attitude towards learning languages among high school students based on Gender.

Table 2: Mean score difference and t-test of attitude towards learning languages among high school students based on Gender.

\begin{tabular}{|l|c|c|c|c|c|c|c|}
\hline Gender & N & Mean & S. D & df & t-value & p-value & Result \\
\hline Male & 156 & 103.39 & 9.076 & & & & \\
\cline { 1 - 5 } Female & 144 & 102.81 & 8.790 & 299 & .560 & .576 & N. S \\
\hline
\end{tabular}

Table 2 shows the mean score difference of attitude towards learning languages among high school students based on Gender. The calculated t-value is statistically not significant at 0.05 levels and hence, the hypothesis 2 is rejected. It can be concluded that there is no significant difference of attitude towards learning languages among high school students based on Gender.

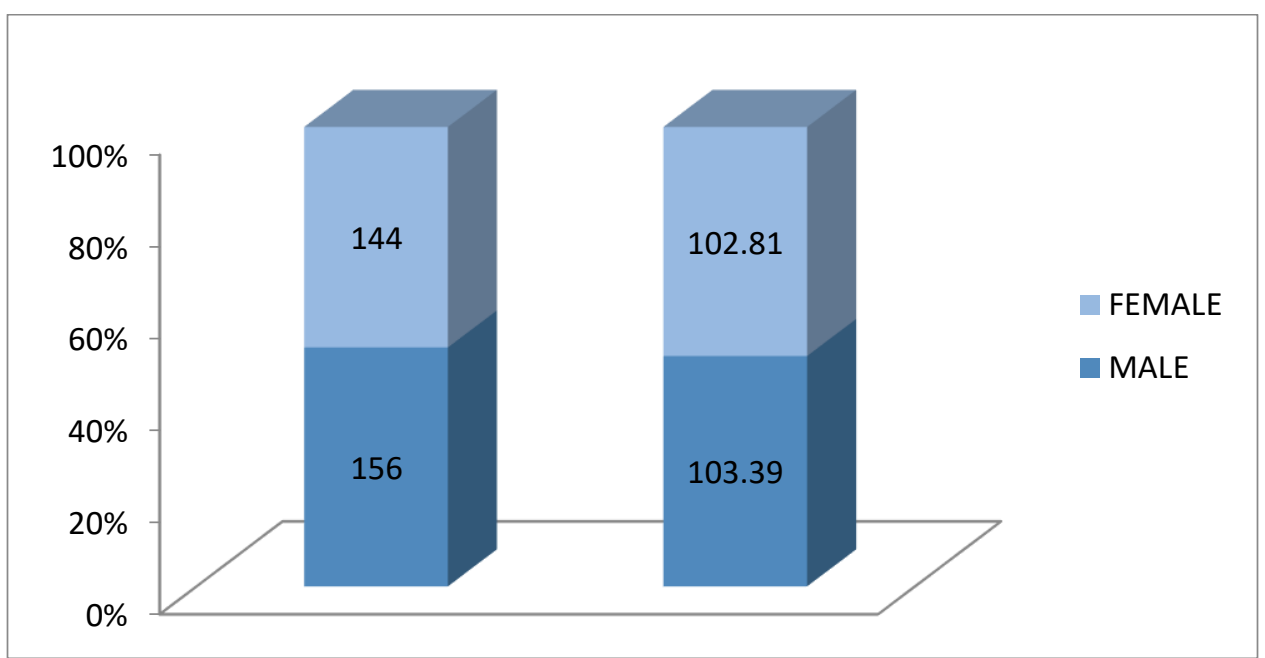

Chart 2: Mean Score Difference and T-Test of Attitude Towards Learning Languages Among High School Students Based on Gender.

\section{Hypothesis: 3}

There will be a significant mean score difference of attitude towards learning languages among high school students based on medium of instruction.

Table 3: Mean score difference and t-test of attitude towards learning languages among high school students based on medium of instruction.

\begin{tabular}{|l|c|c|c|c|c|c|c|}
\hline Medium of Instruction & $\mathbf{N}$ & Mean & S. D & df & t-value & p-value & Result \\
\cline { 1 - 6 } Malayalam & 159 & 102.69 & 8.804 & & & & \\
\cline { 1 - 6 } English & 141 & 103.60 & 9.077 & 299 & .881 & .379 & N. S \\
\hline
\end{tabular}

Table 3 shows the mean score difference of attitude towards learning languages among high school students based on medium of instruction. The calculated t-value is statistically not significant at 0.05 levels and hence, the hypothesis 3 is rejected. It can be concluded that there is no significant difference in the attitude towards learning languages among high school students based on medium of instruction. 


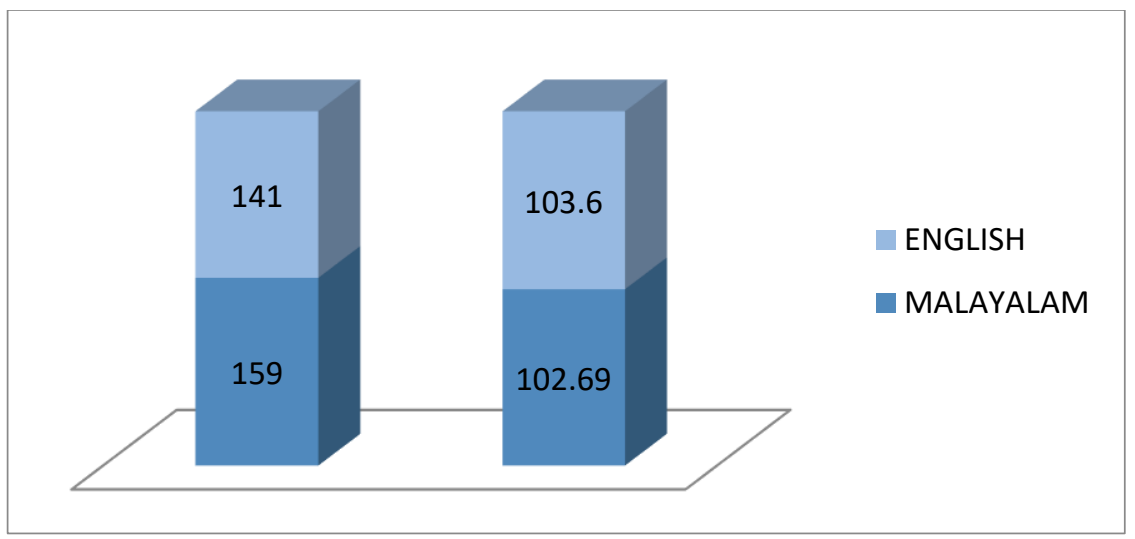

Chart 3: Means Score Difference And T-Test of Attitude Towards Learning Languages Among High School Students Based on Medium of Instruction.

\section{Conclusion}

The findings reveal that totally $26.33 \%$ of high school students belong to low level of attitude towards learning languages, $45.66 \%$ of high school students belong to moderate level of attitude towards learning languages and $28 \%$ of high school students belong to high level of attitude towards learning languages. Thus, it is inferred that there is a difference in the level of attitude towards learning languages among high school students. Here gender and medium play a no role in learning languages.

\section{References}

[1] Golden, S. A. R., \& Regi, S. B. Mobile Learning: A Transformative Tool for Learning and Education.

[2] Khan, S. B., \& Paul, U. M. (1979). Social values of secondary students and their occupational preferences in Guyana.

[3] Leonard, S. T., \& Winsauer, P. J. (2011). The effects of gonadal hormones on learning and memory in male mammals: a review. Current Zoology, 57(4), 543-558.

[4] Regi, S. B., \& Golden, S. A. R. (2014). A Study on Educational Loan Availed By Students in Trichy City. Journal of International Academic Research for Multidisciplinary (Jiarm), 2(1).

[5] Shank, R. (2006). 'Blended e-Learning. on line, date accessed, 15(11), 2007.

bora.uib.no/bitstream/handle/1956/7270/106782449.pdf;sequence=1https://2012books.lardbucket.org /...communication.../s03-02-functions-of-language.h... 